\title{
ORESINAI Better psychological health PAPER is associated with weight stability in women with eating disorders
}

\begin{abstract}
A. Darby ${ }^{*}$, P. Hay**, F, Quirk***, J. Mond ${ }^{* * * *}$, P.G. Buemer ${ }^{r * * * *}$, S.I. Paxton ${ }^{* * * *}$, and L. Kernedy*

*School or Medicine, lames Cook Lniversity. Queensland. Australia. * School of Nedicine. (iniversiny of

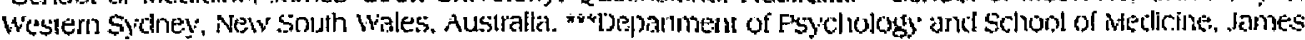

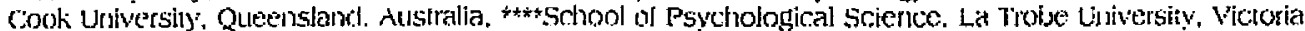
Australia. ****\$School of Public Heabtu, Trojical Medicine and Rehabiliation Sciences. James Cook Ltniversily: Queensland. Australia
\end{abstract}

ABSTRACr. AIM: To explore the associations between changes in weight, eating disorder psychopathology and psychological distress in a community sample of women with eating disorders over two years. METHOD: One hundred and twenty two women identified with disordered eating in a baseline population survey agreed to participate in a follow-up study, of whom $87(71 \%)$, mean age $28 \pm 6.2$, completed the two-year follow-up. Body mass index, eating disorder psychopathology, p.sychological distress, and clemographic details were assessed at both time points. RESULTS: Over the two years there was a moan weight gain of $1.76 \mathrm{~kg}$ $(S D=7.03), 11(13 \%)$ women lost $\geq 5 \mathrm{~kg}, 25(29 \%)$ gained $\geq 5 \mathrm{~kg}$, and $49(58 \%)$ remained weight stable (i.e., within $5 \mathrm{~kg}$ of baseline weight). Comparisons between those who had Jost, gained and remained weight stable showed few significant differences, however, women who remained weight stable were the least psychologically disiressed at baseline and those who lost weight had the greatest reduction in shape concern. Body mass index at baseline, and change in level of binge eating episodes were not associated with weight change. CONCLUSIONS: Disordered eating behaviours have little influence on weight change over two years in community women with disordered eating. Low levels of psychological distress at baseline may promote weight stability. Concerns about shape are likely to increasc with increased weight. (Fating Weight Disord. 14: 13-22, 2009). ${ }^{2} 2009$, Eclitrice Kurtis

\section{INTRODUCTION}

Whilst often regarded as distinct problems, eating disurders and weight disorders have many common characteristics, including dieting behaviour, binge eating, poor body inage and psychosocial difficulties (18). Our recent work has indicated that community women with obesity have significantly higher levels of dietary restraint, eating concern, weight concern, shape concern, binge eating, misuse of diuretics, use of diet pills and fasting compared to other women, and that in women with obesity eating concern, weight concern, shape concern, dietary restraint and younger age predicted psychological distress in a multivariate model (9). Weight is an important oulcome variable in eating disorders with the problems of obesity in relation to the development of chronic lifestyle disease such as diabetes mellitus and cardiovascular disease well documented $(10,11)$, and research showing increased mortality for both obese and underweight people (12).

Work examining relationships amongst disordered eating psychopathology, obesity, psychological distress and psychosocial quality of life has found binge eating (13, 14), and more recently weight and shape concerns (15), to be the main factors related to the psychosocial quality of life and general psychological distress independent of weight. This is in agreement with numerous cross-sectional studies showing no clear relationship between levels depression and obesity status (16).

In a 20-year prospective study on weight and psychopathology in a general community sample of adults, Hassler et al. (17) found binge eating to be associated with being overweight and with increased weight gain. Many cross-sectional studies have found similar associations $(1,18-20)$ In contrast in a 4-year prospective study on adolescent girls, Stice et al. (21) found binge 
eating did not predict obesity onse, and that other behaviours congruent with eating disorders, including self-reported dietary restraint, extreme weight control behaviours such as vomiting and laxative misuse, and factors such as depressive symptoms and perceived parental obesity, predicted obesity onset over time. Neumark-Sztainer et al. (22) also found that dieting and unhealthful weight control behaviours at baseline were related to both weight gain and binge eating 5 years later; however they did nol report on the relationship between weight gain and binge eating.

Few studies, other than those on treatment effects, have examined weight outcomes in people with cating disorders prospectively. One study on the course of binge eating disorder (BED) and bulimia nervosa (BN) over a 5year period, found obesity increased from $22 \%$ to $39 \%$ in participants with BED and from $12 \%$ to $20 \%$ in participants with BN. BED suffers gained an average of $4.2 \pm 9.8 \mathrm{~kg}$ and those with $\mathrm{BN}$ gained $3.3 \pm 10.1 \mathrm{~kg}$ in this time frame (23).

This study aimed at exploring the relationship between change in weight and eating disorder psychopathology in community women with disorclered eating over two years. We hypothesised that in this sample of women with disordered eating weight would increase and there would be a positive association between disordered eating behaviours (binge ealing, fasting, and purging) and increase in weight. We also predicted that higher psychological distress at baseline would be associated with weight gain. There were no specific hypotheses on the relationship between weight change and eating disorder cognitions, i.e. perceived clietary restraint, eating concerns, weight concerns and shape concerns, or with psychological distress, as this part of the study was exploratory.

\section{METHOD}

Design and participant recruitment

Community women identified with disordered eating were followed to two years. The first year of the follow-up study was a randomised controlled trial (RCT) of a menlal health literacy intervention compared to a. no intervention control (24).

Participant recruitment took place in three phases. First, in 2003-2004 we conducted the Women's Health and WelI-Being Study, a large-scale epidemiological study of disability and health-service utilization associated with the more commonly occurring (bulimic-type) eating disorders among young adult women in the community (25). At this phase, self-report questionnaires were posted to a sample of 10,000 female residents, aged $18-42$, selected randomly from the electoral roll of the Australian Capital Territory (ACT) region of Australia (population 323,000), a highly urbanized region which includes the city of Canberra. A total of 5255 individuals responded to the phase-one questionnaire which included measures of eating disorder psychopalhology, height and weight, psychological distress. quality of life, socio-demographic infornation, and self-reported height and weight. Three hundred and twenty-four respondents who met the screening criteria lbased on the Eating Disorder Examination Questionnaire (EDE-Q) (26)] and who indicated a willingness to be contacted at a future date participated in the second phase of the study, involving administration of a structured interview for the assessment of Diagnostic and Statistical Manual of Mental Disorders-Fourth Edition (DSM-IV) eating disorders, namely the Eating Disorder Examination (EDE, 12" edition) diagnostic items (27).

At the thirc phase, 185 women with eating disorder symptoms of clinical severity, namely (i) shape and/or weight concerns of at least moderate importance (score $\geq 4$ on the EDE) during the current three months, and/or (ii) one or more regular eating disorder behaviour(s) such as objective and/or subjective bulimic episodes and extreme weight control behaviour(s), and who did not have anorexia nervosa [DSM-IV criteria (28)], were invited (by JM) to participate in a follow-up study. None were excluded because of anorexia nervosa. One hundred and twenty-two $(66 \%)$ women agreed and were randomised to an intervention or a control group. They did not differ in age (mean 28 years in both groups) or level of eating disorder symptoms from the 63 who did not participate (global EDE-Q mean of 3.7 and 3.8 respectively, $p=0.72)$. Ninety (74\%) completed 6 months, $102(84 \%)$ completed 12 -month followup, and 87 women $(81.7 \%)$ completed the twoyear followi-up.

At baseline half the women ( $N=61)$ were given a mental health literacy package about eating clisorders, effective treatments, a list of services indicating where to seek help and purchasing information on a self-directed treatment manual. The control group $(\mathrm{N}=61)$ were given a list of services only. At the end of year one the control group was also posted the intervention. The results of the RCT have been published elsewhere (24). The present study reports the findings at two years of fol. low-up. 
Of the 122 women in the RCT, 87 women $(71 \%)$ completed the two-year follow-up at a median of 2.27 years (mean $=2.29, S D=0.15$ ). Women who completed the follow-up were more likely to have achieved education beyond the high school certificate than women who did not complete the follow-up $(\mathrm{N}=35 ; 55.3 \%$ versus $47.1 \% ; \mathrm{p}=0.036)$. Of the women who completed the follow-up, $42.5 \%$ had been seeking professional help for an eating problem before the baseline assessment compared to $17.1 \%$ of the women who did not complete the follow-up $(p=0.011)$. None of the other socio-demographic characteristics, measures of severity of eating disorders, and measures of psycho-pathology assessed at baseline, differed between women who completed and women who did not complete the follow-up:

The ACT Human Health Research Ethics Committee provided ethics approval for the baseline assessment and approval for the follow up study was provided by the James Cook University Human Ethics Conmmittee. All participants gave written informed consent.

\section{Measures}

Weight status

Change in weight over two year's was calculated from self-reported weight at both time points (weight at 2 years - weight at baseline). in this study weight stability was classified as those who at two years remained within $5 \mathrm{~kg}$ of their baseline weight, weight gain was classified as greater. than or equal to $5 \mathrm{~kg}$ positive weight change, weight loss was classified as greater than or equal to $5 \mathrm{~kg}$ negative weight change. There is no universally accepted cut off points for what is considered weight stability, or weight loss or gain, and past research has used a wide range of classification meth. ods. However, the amount of $5 \mathrm{~kg}$ has been used in the past to describe major weight gain (29), and a weight loss of $5 \mathrm{~kg}$ used to describe successful dieters (30); this cul off point also helps to differentiate between women who have had small fluctuations in weight, and those who have had a significant weight change.

Body mass index (BMI, $\mathrm{kg} / \mathrm{m}^{2}$ ) was also calculated from self-reported height and weight. Classification of weight was completed using the classification scheme outlined by the World Health Organisation and utilised in the Australian Clinical Practice Guidelines for the Management of Overweight and Obesity in Adults (31). Underweight BMI <18.5, normal weight $\mathrm{BMI} \geq 18.5$ and $<25$; overweight $\mathrm{BMI} \geq 25$ and $<30$, obesity $\mathrm{BMI} \geq 30$ (27).
Eating Disorder Examination Questionnaire (EDE-O)

The EDE-Q $(26,32)$ is a 36 -item self-report measure derived from the EDE (27). The EDE-Q focuses on the past 28 days and is scored using a 7-point, forced-choice, rating scheme. Subscale scores relating to dietary restraint, eating concerns, concerns about weight and concerns about shape - and a global score are derived from the 22 items addressing these attitudinal aspects of eating disorder psychopathology. In this study, however, the scoring system for dietary restraint subscale is altered so that it does not take into account the item on fasting. This is because fasting is assessed as an actual behaviour "Have you gone for" long periods i 8 hours or morel without eating anything in order to influence your shape or weight", whereas, the ratings on other items in the subscale assess attempted dielary restriction regardless of their success, e.g. "Have you tried to avoid eating any foods which you like in order to influence shape or weight?". Problems with the internal consistency of the fasting itern of the EDE-Q have been reported previously (33). Frequencies of other eating disorder (overeating and compensatory) behaviours are also assessed in terms of the total number of episodes occurring during the past four weeks or in the case of fasting 7 options of various frequencies. Objective bulimic episodes (eating episodes with an unusually large amount of food consumed and the experience of loss of control) and subjective bulimic episodes (eating episodes where there was a loss of control and the participant ate more than they would like, however the amount was considered not large for the situation) were combined into an overall score of bulimic episodes. Self-induced vomiting, laxative, and diuretic misuse as a means of controlling shape or weight, were combined into an overall score of purging. Hard exercise was also assessed with reference to the behavjour being used as a means of controlling shape and weight. Fasting was assessed as described above. Reliability and validity of the EDE-Q have been demonstrated in both community and clinical samples (with the exception of overestimation of the binge eating items $)(33,34)$.

\section{Kessler-10 item distress scale $(\mathrm{K}-10)$}

General psychological distress (depression and anxiety) were assessed with the $\mathrm{K}-10$. It has been designed to detect psychological distress and screen for anxiety and depression in the general population (35), and has been used in our previous eating disorder research (e.g. 37). Internal consistency of items is high (e.g. alpha $0.93(36)]$, as is its sensitivity in detecting 
non-specific psychological distress in community surveys (36). The frequency of each of 10 depressive or anxiety symptoms is measured on a scale from one to five. In the present study, coding of the response options was such that total scale scores ranged from 10 to 50 , with higher scores indicating greater symptomatology. In an Australian community survey the K-10 had a mean score of 14.2, median of 12 , range $10-50$, and mean of $13.9 \mathrm{in}$ women only, and only $3 \%$ of all respondents scored $\geq 30(35)$.

Help seeking for an eating problem

Participants were asked if they had spoken to or sought advice from a range of professional people including a general practitioners, psychiatrists, psychologists, counsellors, social workers, dietitian or nutritionist, in relation to a problem with their eating, e.g. "such as eating too much in one go, feeling that your eating is out of control, been preoccupied with what you can eat or when you can eat, with burning up calories, or other problems like this?". An overall variable for any professional help seeking for an eating problem over the two years was then derived.

\section{Statistical analysis}

Data analysis was conducted using the Statistical Package for the Social Sciences, SPSS, version 14. Data were inspected for normality and non-parametric tests were used accordingly. Wilcoxon signed rank test $(Z)$ was used to examine significant changes between base and two years in the overall sample. To assess the relationship between weighl change and other variables Spearman's rho correlation coefficient $(\mathrm{r})$ was utilised. Differences in baseline BMI, as well as baseline and change in levels of ealing disorder psychopathology, and psychological distress, between those who gained weight, lost weight and remained weight stable (within $5 \mathrm{~kg}$ of baseline reporled weight) were tested using Chi-Square tests $\left(\chi^{2}\right)$ for categorical variables and Kruskal-Wallis $\left(k-w \chi^{2}\right)$ tests for continuous variables. Where cell sizes were smail, data was aggregated. Pust hoc analyses were conducted for variables which reached or approached statistical significance, to assess in further detail how the three weight change groups were different to one another. Post-hoc tests involved the aggregation of data, and the use of Fisher's exact tests for categorical variables, and the Mann Whitney $U(Z)$ tests for continuous variables. Potential confounding variables in the differences between weight change groups, including socio-demographics, pregnancy, help seeking for an eating problem, and $\mathrm{RCT}$ condi- tion from the first year of the sludy were tested as above. To correct for multiple tests the significance level was set at $p<0.01$.

\section{RESULTS}

Participant features at two year follow-up A demographic profile of the 87 young women who completed the two-year follow-up, and weight status and eating disorder behaviours at baseline are displayed in Table 1 . The mean age of the women at baseline was 28.21 years $(S D=6.18)$. The majority of these women (91\%) were born in Australia, $48.4 \%$ were living single at the time of baseline assessnent, and $66 \%$ were in full-or part-tine paid employment. The median BMI at baseline was $25.2 \mathrm{~kg} / \mathrm{m}^{2}$. Sixty-one point five percent of women reported a clinical level of binge ealing

TABLE I

Description of socio-demographics, weight stalus and ealing disorder behoviours of women at baseline.

\begin{tabular}{|c|c|}
\hline Meosyre & $\%$ \\
\hline $\begin{array}{l}\text { Couniry of birth (N=87) } \\
\text { Australia } \\
\text { Othër }\end{array}$ & $\begin{array}{c}91 \\
9\end{array}$ \\
\hline $\begin{array}{l}\text { Marilal status ( } N=87) \\
\text { Married ar living as married } \\
\text { Single } \\
\text { Separaled / Divorced }\end{array}$ & $\begin{array}{r}51 \\
47 \\
2\end{array}$ \\
\hline Children (one or ntore] $(\mathrm{N}=87)$ & 33 \\
\hline 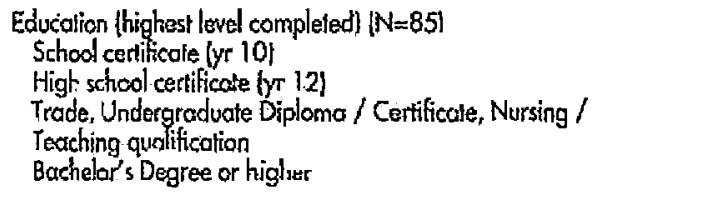 & $\begin{array}{l}5 \\
40\end{array}$ \\
\hline 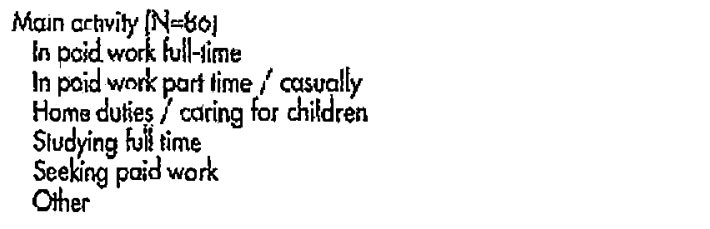 & $\begin{array}{l}16 \\
1 \\
1\end{array}$ \\
\hline $\begin{array}{l}\text { Weight status }(\mathrm{N}=85) \\
\text { Obese } \\
\text { Orerweight } \\
\text { Nomal weight } \\
\text { Underweight }\end{array}$ & \\
\hline $\begin{array}{l}\text { Any' cecurrence of eating disorder behoviours over one month: (N=87) } \\
\text { Binging (subjective or objective bulimic episodes) } \\
\text { Purging (vomiting, duretic or laxative use to control shape or weight) } \\
\text { Fasting (E or more hours wilhout food to infivenice shope or weight) } \\
\text { Exercise (hard exercise to influence shupe or weight) }\end{array}$ & \\
\hline
\end{tabular}

IAny occurrence of eating disorder behaviours referred to one or more episodes in the month prior to the guestionnatre. 
and $9 \%$ a clinical level of purging at baseline. During the follow-up time $10.7 \%$ of the women became pregnant. At two years of follow-up the mean EDE-Q global score was 3.1 (SD=1.1), $59.8 \%$ of women had experienced at least one day out of role during the past four weeks, and the mean SHort Form-12 mental component score was 38.0 ( $S D=13.3$ ).

Fifteen (13\%) of participants met diagnostic criteria [or BN, $18(15 \%)$ for BED, $54(44 \%)$ had eating disorder not otherwise specified (EDNOS; defined as having extreme weight and/or shape concerns and a regular ED behaviour throughout the preceding three months) and the remainder $(\mathrm{N}=35,29 \%)$ had sub-threshold disorders with either current extreme concerms and/or regular eating disorder behaviour(s) at a leve\} of clinical severity.

The present study reports on factors related to change in weight at 2 years.
Participants' woight change

Two of the 87 women did not supply detals regarding weight at both time points and thus could not be included in any further analysis. Overall the mean change in weight was +1.76 $\mathrm{kg}(\mathrm{SD}=7,03)$, greatest decrease in weight was $25 \mathrm{~kg}$, greatest increase in weight was $20 \mathrm{~kg}$. Twenty-five (29\%) women gained $5 \mathrm{~kg}$ or more, $49(57 \%)$ remained weight stable within $5 \mathrm{~kg}$ of baseline, and $11(13 \%)$ lost $5 \mathrm{~kg}$ or more. The majority of this sample indicated that they were trying to lose weight at the two year follow-up assessment $(\mathrm{N}=79,93 \%)$.

Participants change in euting disorder" psychopathology and psychological distress

The global EDE-Q scores at baseline were bigh [median $=3.58$, IQP $(3.18,3.86)$, mean= $3.75,5 \mathrm{D}=0.82$ ], compared to a comnunity sam-

TABLE 2

Descriptive information on baseline psychopathology according to change in weiaht category.

\begin{tabular}{|c|c|c|c|c|c|c|c|}
\hline Boselina measures & & $\begin{array}{c}\operatorname{Los}\{\geq 5 \mathrm{~kg} \\
N=1^{i}\end{array}$ & $\begin{array}{l}\text { Weight stoble } \\
\qquad N=d 9\end{array}$ & $\begin{array}{l}\text { Gained } \geq 5 \mathrm{~kg} \\
N=25\end{array}$ & $k-w^{2} z^{2}$ & of & D \\
\hline BMI $\left[\mathrm{kg} / \mathrm{m}^{2}\right]$ & $\begin{array}{l}\text { Median } \\
\text { (IQR) }\end{array}$ & $\begin{array}{c}29.41 \\
(21.83,36.00)\end{array}$ & $\begin{array}{c}24.76 \\
\{21.05,28.24\}\end{array}$ & $\begin{array}{c}25.67 \\
(22.97,32.19)\end{array}$ & 5.443 & 2 & 0.066 \\
\hline $\begin{array}{l}\text { EDEQ } \\
\text { Aftempled restriclion }\end{array}$ & $\begin{array}{l}\text { Median } \\
\text { (IQR) }\end{array}$ & $\begin{array}{c}4.50 \\
(2.50,5.00\}\end{array}$ & $\begin{array}{c}4.00 \\
{[2.63,5.00]}\end{array}$ & $\begin{array}{c}4.50 \\
(2.38 ; 5.38)\end{array}$ & 0.326 & 2 & 0.850 \\
\hline $\begin{array}{l}\text { EDEQ } \\
\text { Weighi concem }\end{array}$ & $\begin{array}{l}\text { Medion } \\
\text { (IQR) }\end{array}$ & $\begin{array}{c}3.80 \\
(3.40,5.40)\end{array}$ & $\begin{array}{c}4.00 \\
{[3.20,4.80]}\end{array}$ & $\begin{array}{c}4,00 \\
(3.80,4,70\}\end{array}$ & 0,390 & 2 & 0.823 \\
\hline $\begin{array}{l}\text { EDEQ } \\
\text { Shape concern }\end{array}$ & $\begin{array}{l}\text { Median } \\
\text { [QRS }\end{array}$ & $\begin{array}{c}5.50 \\
\{4,75,5.75\}\end{array}$ & $\begin{array}{c}4.75 \\
{[3.94,5.19]}\end{array}$ & $\begin{array}{c}5.06 \\
14.00,5.56\end{array}$ & 5.147 & 2 & 0.076 \\
\hline $\begin{array}{l}\text { EDEQ } \\
\text { Ealing concern }\end{array}$ & $\begin{array}{l}\text { Median } \\
\text { (IOR) }\end{array}$ & $\begin{array}{c}2.60 \\
\{1,40,4.20\}\end{array}$ & $\begin{array}{c}2.80 \\
(2.20,3.90)\end{array}$ & $\begin{array}{l}3.20 \\
(2.10,4.00)\end{array}$ & 0.388 & 2 & 0.824 \\
\hline Psychodogicol dishress $(K-10)$ & $\begin{array}{l}\text { Median } \\
\text { (IQR) }\end{array}$ & $\begin{array}{c}21.50 \\
{[15: 50,32,50)}\end{array}$ & $\begin{array}{c}18.00 \\
(15.00,23.00\}\end{array}$ & $\begin{array}{c}26.00 \\
(20.00,29.00)\end{array}$ & 9.049 & 2 & $0.011^{\circ}$ \\
\hline \multicolumn{8}{|l|}{ Baseline behaviours } \\
\hline $\begin{array}{l}\text { 8ulimic episodda } \\
\text { Any? } \\
\text { Regulor }\end{array}$ & 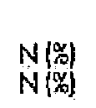 & $\begin{array}{l}10,91] \\
7(64)\end{array}$ & $\begin{array}{l}43 \cdot(88) \\
34(69)\end{array}$ & $\begin{array}{l}23.92] \\
20 .[80]\end{array}$ & $\begin{array}{l}0.345 \\
1.332\end{array}$ & $\begin{array}{l}2 \\
2\end{array}$ & $\begin{array}{l}0.842 \\
0.514\end{array}$ \\
\hline $\begin{array}{l}\text { Purging episodes } \\
\text { Any } \\
\text { Regular }\end{array}$ & 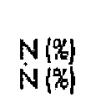 & $\begin{array}{l}2 \text { [18\} } \\
2\{18\}\end{array}$ & $\begin{array}{l}8(16) \\
5(10)\end{array}$ & $\begin{array}{l}9(36) \\
6(24)\end{array}$ & $\begin{array}{l}3.818 \\
2.513\end{array}$ & $\begin{array}{l}2 \\
2\end{array}$ & $\begin{array}{l}0.148 \\
0.285\end{array}$ \\
\hline $\begin{array}{l}\text { Fasting } \\
\text { Anyy } \\
\text { Regular }\end{array}$ & $\begin{array}{l}N(\%) \\
N(\%)\end{array}$ & $\begin{array}{l}4(36) \\
2(18)\end{array}$ & $\begin{array}{l}16(33) \\
5(10)\end{array}$ & $\begin{array}{l}12(48) \\
4(16)\end{array}$ & $\begin{array}{l}1.670 \\
0.802\end{array}$ & $\frac{2}{2}$ & $\begin{array}{l}0.434 \\
0.670\end{array}$ \\
\hline $\begin{array}{l}\text { Exercise } \\
\text { Any } \\
\text { Regulas } \\
\text { Exireme (everyday) }\end{array}$ & $\begin{array}{l}N(:) \\
N(9) \\
N(\%)\end{array}$ & $\begin{array}{c}7\{64\} \\
7\{64\} \\
0\end{array}$ & $\begin{array}{l}34(69) \\
31(63) \\
5(10)\end{array}$ & $\begin{array}{c}12(48) \\
12(48) \\
1(4)\end{array}$ & $\begin{array}{l}3.235 \\
1.713 \\
1.931\end{array}$ & $\begin{array}{l}2 \\
2 \\
2\end{array}$ & $\begin{array}{l}0.198 \\
0.425 \\
0.381\end{array}$ \\
\hline
\end{tabular}

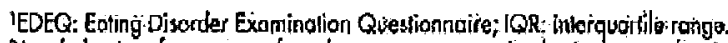

2Any behovicur frequency refersed to one or more opisades in the month prior to the questionnoine

3Regutar behoviour frequency referred to lunkss otherwise skiled) an averoge of one episodes of the behcriour: per week in the month prior to the questronnare.

'Post-hoc tinding weight stable group $x$ weight boss or woight gain grous $\{0=0.004$ ) - see lext. 
ple of women in the general population of the $A C T(N=5255$ mean $=1.52, S D=1.25)$ (32). There was a significant reduction in EDE-Q global score at two years compared to baseline in the overall sample $(Z=-4.821, \mathrm{p}<0.0001)$, however this score remained high at two years Imedi$a_{n}=3.32$, IQR $(2.40,3.86)$, mean $\left.=3.15, S D=1.15\right]$. A similar reduction was found for all EDEQ subscale scores (all $Z<-3.030$, all $p<0.002$ ). There was also a significant reduction in binge eating $(Z=-3.829, p<0.0001)$, however levels of purging, fasting and exercise did not significantly change (all $Z>-0.975$, all $p \geq 0.330$ ). The baseline psychological distress score was high lmedian $=20.00, I Q R(16.00,27.00)$, mean $=21.96$, $\mathrm{SD}=8.11$ ) (33)], and did not significantly change at two years $(Z=-1.187, p=0.235)$.

\section{Association between weight change, and levels of eating disorder psychopathology and psychological} distress in the overall sumple

Correlations between change in weight, and baseline levels of eating disorder behaviours, EDE-Q subscale scores, psychological distress, and BMI in the overall sample $(\mathrm{N}=85)$ were examined. Howevel, no significant relationships were found (all $r \leq 0.181$, all $p \geq 0.10$ ). Similarly, change in levels of eating disorder behaviours, EDE-Q subscale scores, and psychological distress (i.e. year two score or frequency minus baseline score or [requency) at two years did not significantly correlate with change in weight, although there were trends with change in level of shape concern approaching significance $\left(r_{s}=0.269, p=0.013\right)$ and change in level of weight concern approaching significance $\left(r_{s}=0.235, p=0.032\right)$, alt other $r_{5} \leq 0.206$, all $p \geq 0.061$.

\section{Weight gain, weight loss and weight stable participants - between group differences}

Characteristics of baseline weight, eating disorder features and level of psychological distress in the three weight change category groups, and summary stalistics of between group analyses are reported in Table 2 . The only baseline variable which had significant differences between weight change category groups was psychological distress. As the posthoc Mann Whitney U tests indicated, the weight stable group had a lower psychological distress score at baseline than the weight loss or weight gain group $(Z=-2.88, p=0.004)$. Baseline $B M I$ and shape concern showed trends in being different amongst the three weight groups. Post-hoc Mann Whitney U tests indicated the weight stable group had a trend in being a lower weight at baseline compared to weight loss or weight gain group $(Z=-2.156$, $p=0.031$ ), and the weight loss group showed a trend in being the heaviest compared to the weight stable or weight gain group $(Z=-1.76$, $p=0.078$ ). For shape concern, the weight loss group showed a trend in having the highest shape concern at baseline compared to the weight stable or weight gain group $(Z=-1.86$, $p=0.063$ ).

Changes in levels of eating disorder psychopathology and psychological distress at two years were calculated (i.e. year two score or frequency minus baseline score or frequency) and between group differences tested (Table 3). Changes in levels of symptomatology over time did not significantly differ between the three weight change groups, although changes in levels of weight concern and shape concern were approaching statistical significance. Posthoc Mann Whitney U tests were performed for these variables approaching significance, and indicated the weight loss group had the greatest reduction in shape concern compared to the weight stable or weight gain group $(Z=-2.62$, $p=0.009$ ), and similarly showed a trend in having the greatest reduction in weight concern $(Z=-2.240, p=0.025)$.

\section{Potential confounders in between group differences}

Demographic features, pregnancy, help seeking for an eating problem, and RCT condition from the first year of the study were investigated as possible confounding variables on a participant allocation to weight loss, gain or stability groups. There were no between group differences in marital status $\left(\chi^{2}=7.245, d f=6\right.$, $p=0.299)$, being a mother $\left(\chi^{2}=1.309, d f=2\right.$, $\mathrm{p}=0.520)$, place of birth, $\left(\chi^{2}=1.375, \mathrm{df}=2\right.$, $p=0.503$ ) highest education level achieved $\left(\chi^{2}=5.604, d f=4, p=0.231\right)$, and main work activity $\left(\chi^{2}=9.090, d f=10, p=0.524\right)$. Pregnancy was reported by $13(15 \%)$ women over the two years of the study, however there were no between group differences in reported pregnancies $\left(\chi^{2}=3.487, d f=2, p=0.175\right.$ ). Professional help seeking over the two years for an eating problem was reported by $34(40 \%)$ of the women, however there was no between group differences for this variable $\left(\chi^{2}=2.738, \mathrm{df}=2\right.$, $p=0.254$ ). For RCT condition from the first year of the study, between group differences were approaching significance $\left(\chi^{2}=5.376, d f=2\right.$, $p=0.068$ ), thus a $2 \times 2$ post-hoc Fisher's exact test was performed. Women who had lost weight appeared more likely to have received the intervention ( $\mathrm{N}=9,82 \%$ weight loss group vs. $\mathrm{N}=35,47 \%$ of weight stable or gained); howev- 
TABIE 3

Two year chanae in psychopathology according to change in weight.

\begin{tabular}{|c|c|c|c|c|c|c|c|}
\hline $\begin{array}{l}\text { Change in measurs } \\
\text { af two years }\end{array}$ & & $\begin{array}{c}\text { sost } 25 \mathrm{~kg} \\
\mathrm{~N}=11\end{array}$ & $\begin{array}{l}\text { voight stabl } \\
N=49\end{array}$ & $\underset{N=25}{\operatorname{Ganned} 23 \mathrm{~kg}}$ & $k-w^{2} \cdot x^{2}$ & of & p \\
\hline $\begin{array}{l}\text { EDEQI } \\
\text { altemplat'rastriction }\end{array}$ & $\begin{array}{l}\text { Median } \\
\text { (IOR) }\end{array}$ & $\begin{array}{c}0.00 \\
-1.50,0.751\end{array}$ & $\begin{array}{c}.0 .75 \\
1.75,0.25)\end{array}$ & $\begin{array}{c}-0.75 \\
|-1.63 ; 0.25|\end{array}$ & 1.128 & $\dot{4}$ & u.564 \\
\hline $\begin{array}{l}\text { EDEQ } \\
\text { woight soncern }\end{array}$ & $\begin{array}{l}\text { Median } \\
\text { (KoR) }\end{array}$ & $\begin{array}{c}1.20 \\
-1.60,-0.40]\end{array}$ & $\begin{array}{c}0.60 \\
{[-1.0,0.40]}\end{array}$ & $\begin{array}{c}-0.30 \\
(-0.60,0.75)\end{array}$ & $7: 459$ & 2 & 0.024 \\
\hline $\begin{array}{l}\text { EDEQ } \\
\text { shape concern }\end{array}$ & $\begin{array}{l}\text { Mediun: } \\
\text { [KaR] }\end{array}$ & $\begin{array}{c}-1.13 \\
-3.00,0.381\end{array}$ & $\begin{array}{c}-0.50 \\
1 \cdot 06,0.13)\end{array}$ & $\begin{array}{c}0.00 \\
1-0.81,0.44)\end{array}$ & 8.356 & 2 & $2.015^{*}$ \\
\hline $\begin{array}{l}\text { EDEQ } \\
\text { eating cencerr }\end{array}$ & $\begin{array}{l}\text { Median } \\
\text { [OQRR] }\end{array}$ & $\begin{array}{c}0.40 \\
-2.20,0.80\end{array}$ & $\begin{array}{c}-0.60 \\
=1.80 ;=0.201\end{array}$ & {$[-1 ; 20,0.70\}$} & 2.619 & $?$ & 0.271 \\
\hline Bulimic episodes & $\begin{array}{l}\text { Median } \\
(K Q R)\end{array}$ & $\begin{array}{c}2.50 \\
10.75,4.75\end{array}$ & $\begin{array}{c}3.00 \\
(-9.50,2.501\end{array}$ & $\begin{array}{c}-7: 00 \\
16,00,000\}\end{array}$ & 1.912 & 2 & 0.384 \\
\hline Purging & $\begin{array}{l}\text { Median } \\
\text { (KQR) }\end{array}$ & $\begin{array}{c}0.00 \\
(0.00,0.00)\end{array}$ & $\begin{array}{c}0.00 \\
10.00,0.001\end{array}$ & $\begin{array}{c}0.00 \\
(-0,50,0.00\}\end{array}$ & 0.965 & 2 & 0.617 \\
\hline Fasting & $\begin{array}{l}\text { Median } \\
\text { (IQR) }\end{array}$ & $\begin{array}{c}0.00 \\
(0.00,1,00)\end{array}$ & $\begin{array}{c}0.00 \\
\{-1,00,0.00\}\end{array}$ & $\begin{array}{c}0,00 \\
(1.00 ; 0.50\}\end{array}$ & 1.341 & 2 & 0.512 \\
\hline Exercise & $\begin{array}{l}\text { Médion } \\
\text { (IQR) }\end{array}$ & $\begin{array}{c}0.00 \\
\sqrt{-2.00}=0.00\end{array}$ & $\begin{array}{c}0, \alpha \\
(-7.50,6.00)\end{array}$ & $\begin{array}{c}0.00 \\
{[-7.00,0.00)}\end{array}$ & 0.107 & 2 & 0.948 \\
\hline Psycrological distress (K-10 & $\begin{array}{c}\text { Mediar } \\
(Q \mathrm{QR})\end{array}$ & $\begin{array}{c}0.00 \\
\{-5.00,3.25\end{array}$ & $\begin{array}{c}1,00 \\
\cos 3.651\end{array}$ & $\begin{array}{c}1.00 \\
{[6.00,8.00}\end{array}$ & 0.686 & 2 & 0.710 \\
\hline
\end{tabular}

'EDEQ: acting disorder excminalion questionnare, KQR: intermuartile rcnge.

"Post-hee finding weight loss group < weighl sleble or weight gain group (p-0.009)- see lext.

er, this effect did not reach statistical significance $(p=0.050)$.

\section{DISCUSSION}

We hypothesised that weight would increase in this sample of women with disordered eating: overall there was a small mean weight gain, and $29 \%$ gained $5 \mathrm{~kg}$ or more, however. the majority $(58 \%)$ of these women remained weight stable (within $5 \mathrm{~kg}$ of baseline weight] over the two-year period. Despite weight loss been highly desired and women displaying a range of behaviours and attempted dietary restriction to cuntrol weight, weight loss was relatively uncommon. The results have some similarities with the findings of Fairburn et al. (23) in their prospective study of women with bulimic eating disorders, which showed weight gain and increase in obesity over a five-year period. The weight gain in the current sample was not as great: however, it was observed only during a two-year period. In contrast, this study showed many wonken remained weight stable and a small minority lost a substanlial amount of weight over two-year period.

The majority of participants in this study were overweight or ubese at baseline, and a small number were underweight. These weight risk factors are associated with long-term increased morbidity and mortality due to associated ilness (10-12). Thus, weight and change in weight are important outcomes for women with eating disorders, with neither movement into or towards underweight or movement into or toward obesity being a positive outcome based on the current evidence.

In contrast to studies conducted in general community samples or populations of adolescents $(17,21,22)$, and in discord with our hypothesis, neither binge eating nor compensatory weight control behaviours were associated with change in weight over time in this sample of women with eating disorders. This lack of association may be due to the general decline in binge eating belhaviours over the two years in this sample, thus whilst reduction in binge eating may not be associated with weight loss, as few women increased levels of binge eating in this sample we cannot determine if this is associated with weight gain. This is congruent to treatment studies on bulinia and binge eating which show that whilst cognitive behavioural therapy is effective in reducing eating disorder behaviours and psychopathology (including reduction of binge eating), they are unlikely to be effective alone in reducing body weight of women sulfering co-morbid eating disorders and overweight (38). 
Unlike previous research in community women indicating heavier women are more likely to put on more weight (39), in this selected sample of women with disordered eating there was a statistical trend for those who had the highest BMI at baseline to be in the weight loss group, and those with the lowest BMI at baseline to be in the weight stable group. The women in the weight loss group tended to have the highest shape concern at baseline (althotigh not stalistically significant), and at the (wo-year time point, having lost a substantial amount if weight, thay showed the grealest reduction in shape concern. In the overall sample there was a trend for weight gain being positively associated with changing levels of shape concern and weight concern, a finding not unexpected, with preferred shape for women in Western society being slender.

Women who were the least psychologically distressed (a mensure of depression and anxiety) at baseline were more likely to be weight stable at two years. Weight change both positive and negative is recognised as common symptom of depression (40) and is possibly related to changes in food intake and energy expenditure. Although the weight stable group was the least psychologically distressed at baseline, at two years they appeared to have greater increase in level of psychological distress compared to those who had lost weight, although the group differences were not statistically significant. Therefore, over a longer period we would expect psychological distress and shape concern may fluctuate with weight change and stability, and high levels of psychological distress and shape concern will be found to precede periods of weight change in women with chronic disordered eating. In a clinical setting it may be that addressing psychological distress and shape concern is the most effective way of preventing weight gain and weight fuctuations in women with disordered eating.

There are several limitations to this study; firstly the small sample size and sample heterogeneity may lead to type II statistical error. There was also low frecquency of purging and fusting behaviours in this small sample, making it difficult to draw any conclusion in regards to their relationship to change in weight. Thus we recommend further prospective studies on outcome in eating disorders (including weight) be conducted in larger samples. Secondly, the analysis is based on two-time points, which were two years apart, thus we cannot be sure of the extent or influence of symptoms fluctuating up and down within the two years. Thirdiy, the EDE-Q, although widely accepted as a tool for measuring eating disorder psychopatholo- gy in research, does not assess actual dietary restriction and intake well (41). This is a common behaviour in women with eating disorders and separate to attempting to diet (regardless of success) and also separate to fasting, as it is possible to eat regularly and have very low energy intake. Actual dietary intake is possibly more strongly related to change in weight, and physical and mental chronic disease outcome in eating disorder samples. Thus, future studies in this area should obtain greater details on actual dietary intake. Finally, there was a reliance on self-report data for height and weight and only one instrument was used to measure psychological distress.

\section{CONCLUSIONS}

Overweight and obesity are significant problems in women with disurdered eating in the community. However, in this sample change in weight over time did not relate to eating disol'der behaviours, but jelated to concern about sliape and to psychological distress. Further sludies conducted in larger samples which include improved assessment of dietary intake are required over a longer period to assess the relationship between eating disorders, change in weight and chronic disease status. Future research on the merits of weight stability verses weight loss in terms of physical and mental health outcomes in conmunity wonen with eating disorders, particularly those with co-morbid overweight and obesity needs to be conducted.

\section{ACKNOWLEDGEMENTS}

The longitudinal follow'-up research was funded by a grant from the Australian Rotary Health Research Fund. The initial phase of the Women's Health and Well-Being Study was lunded by The Canberra Hospital Private Practice Fund. Australian Capital Territory Health and Community Care and Australian Capital Terrilory Mental Health, and was assisted with funding from the NSW institute of Psychiatry in the form of a research training fellowship for Jonathan Mond. Anita Darby's position as Research Officer (Discipline of Psychiatiy) was supported by James Cook University, School of Medicine and Jonathan Mond's position was supported in 2006 by an internal James Cook University Grant to the School of Mcdicine AVANT group (Chief Investigator Professor Lee Kennedy).

\section{REFERENCES}

1. Hay P.J.: The epidemiology of ealing disorder behaviours: an Australian community-based survey. Int. $\mathrm{J}$. Eat. Disord., 23, 371-382, 1998. 
2. Pearistein $\Upsilon$.: Ealing disorders and comorbidity. Archive of Women's Mental Health, $4,67 \cdot 78,2002$.

3. Wardle J., Waller J., Ropoport L.: Body dissatisfaction and binge eating in obese women: role of restraint and depression. Obes. Res., 9, 778-787, 2001.

4. Schwart2 M., Brownell K.: Obesity and body image. Body Inage. 1, 43-56, 2004.

5. Vander Wal J.S., Thelen M.H.: Eating and body image concerns among obese and average weight children. Adidiclive Behaviours, 25, 775-778, 2000.

6. Jkeda J.P., Lyons P., Schawartyman F., Mitchell R.A Self reported dieting experiences of women with body mass indexes of 30 or more. J. Am. Diet. Assoc., 104. 972-974, 2004.

7. Broberg A.G., Hjalmers 1., Nevonen L. Eating disorders, attachmenl and interpersonal difficulties: a comparison between 18 to 24 year old patients and normal controls. Eur. Eat. Disord. Rev.. 9. 381-396, 2001.

3. Wabitsch M.: Overweight and obesity in Eulopean children: detinition and diagnostic procedures, risk factors and consequences for iater health ontcome. Eur. J. Pediats., 15!, Suppl., S8-513, 2000.

9. Darby A.M., Hay P.I. Mond J.M., Rodigers B.. Owen C.: Disordered eating belaviours and cognitions in young women with obesity: relationship with psy'cholugical status. Int. J. Obes., 31, 376-88'2, 2007.

10. Astrus A., Finer N.: Redefining Type 2 diabetes: 'Diakesily' or 'Obesity Dependant Diabetes Meljitus'? Obes. Rev., 1, 57-50, 2000.

11. Murphy N.F., MacIntyre K., Stewart S., Hart C.L., Hole D., McMurray J.J.V.: Long term cardiovascular consequences of obesity: 20-year follow up of more than 15000 middle-aged men and women (the Renfrew: Paisley study). Eur. Heart J., 2̄, 96-106. 2006.

12. Flegal K.M., Girabard B.I., Williamson D.F., Gail M.F.: Excess deaths associated with underweight. overweight and obesily. J.A.M.A., 293, 1861-1867, 2005.

13. Telch C.F., Agras W.S.: Obesity, binge eating and psychopathology: are they related? Int. J. Eat. Disord., 15, 53-61, 1994.

14. Didie E.R., Fitzgibbon M.: Binge eating and psychological distress: is the degree of obesity a factor? Eating Behaviours, 6, 35-41, 2005

15. Mond .I.M., Rodgers B., Illay P.J., Darby A.. Owen C., Baune B.T., Kennedy L.K.: Obesity and impaimsent in psychosocial functioning in women: the mediating role of eating disorder features. Obesity, 15, 2769-2779, 2007.

16. Faith M.S., Matz P.E., Jorgc M.A.: Obesity-depression associations in the population. J. Psychosom. Res., 53, $935-942,2002$

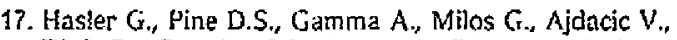
Ejch D., Rossler W., Angst J.; The associations between psychopatholocy and being overweight: $A$ 20-year prospective study. Psychol. Med., 34, 1-11, 2004.

18. French S.A., Jefiery R.W., Sherwoud N.E., NeumarkSztainer D.: Provalonce and correistes of binge eaking in a non clinical syunple of women enrolled in a weight gain prevention program. Int. J. Obes., 23, 576-585, 1999.

19. Hudson J.I., Lalonde J.K., Belry J.M., Pindyck L.J., Bulik C.M., Crow S.J., McElroy S.L.. Laird N.M.. Tsutung M.T., Walsh T., Rosenthal N.K., Pope H.G.: Binge-eating disorder as a distinct familial phenotype in obese individuals. Arch. Gen. Psychiatry, 63, 313$319,2006$.
20. De Zwaan M.: Binge eating disorder and obesity. Int. J. Obes., 25, S51-S55, 2001.

21. Stice E., Presnel] K., Shaw H., Rohde P.. Psychological and behavioural risk factors for obesity onser in adolescent girls: a prospcctive study. J. Cons. Clin. Psychology, 73, 195-202, 2005.

22. Neumark-Sztainer D, Wall M.. Guo J., Story M., Haines J., Eisenberg M.: Obesity, disordered eating, and eatings disorders in a longitudinal study of adolescents: how do dieters fare 5 year later? J. Am. Diet. Assoc.., 106, 559$567,2006$.

23. Fajrburn C.G., Cooper Z., Doll H., Norman P., $O^{\prime}$ Comnor $M$. The natural course of bulimia nervosa and binge eating disorder in young women. Arch. Gen. Psychiatry, 57, 659-665, 2000.

24. Hay P., Mond .I., Paxton S. Rodgers B., Darby A., Owen $C$. What are the effects of providing evidenced based information on eating disurciers and their treatments? A randomised controjled trial in a symptomatic community sample. Early Interv. Psyclialry, ?, 316$324,2007$.

25. Mond J.M., Hay P.J., Rodgers B., Owen C.. Crosby R.: Use of extreme wejght control behaviours with and without binge eating in a community sismple: implics. tions for the classification of bulimic-type eating disorders. Int. J. Ent. Disord., 39, 294-302, 2006.

26. Beglin S.J.. Fairburn C. G. Evaluation of a new instrument for the detection of eating disorders. Psychiatry Res., 44, 191-201. 1992.

$2 \bar{i}$. Fairburn C.C., Cooper $z$.. The eating disorder cxami nation 12th edition. In: Fairburn C.G.. Wilson G.T. (Eds.). Binge eating: nature assessment and treatment. New York, Guilford Press, 1993, pp. 317-360.

28. American Psychiatric Association. Diagnustic and statistical manual of mental disorders, 4th ed. Washington, DC, American Psychiatric Association, 1984.

29. Ball K., Crawtord D., Ireland P., Hodge A.: Patterns and demngraphic predictors of 5-year weight change in a multi-ethnic cohort of men and women in Australiz. Public Heatth Nutr., 6. 269-280, 2003.

30. Lahti-Koski M., Mannisto S., Pietinen P., Vartiainen E.: Prevalence of weight cyctirg and its relstion to henlth indicaturs in Fintand. Obes. Res., 13, 333-341, 2005.

31. National Health and Medical Research. Clinical Practice Gujdelines for the management of overweight and obesity in aduits. Canberra, Commonwealth of Australia, 2003.

32. Mond J.M., Hay P.J., Rodgers B., Owen C.: E.ating Disorder Examination Questionnaire ( $E D E-(O)$ : norms for young adult women. Behav. Res. Ther,., 44, 53-62, 2006.

33. Mond J.M., Flay P.J., Roigers B., Owen C.. Beumont P.J.V.: Validity of the eating disorder examination questionnaire (EDE- $Q$ ) in screening for eating disorders in community samples. Belaav. Res. Ther., 42, 551567, 2004.

34. Mond J.M., Hay P.J., Rodgers B., Owen C., Betmont P.J.V.: Temporal stabilicy of the Eating Disorder Examination Questionnaire (EDE-Q). Int. J. Eat. Disord., 36, 195-203, 2004.

35. Andrews G., Slade T.: Inlerpreting scores on the Kcssler Psycholocrical Distress Scule. AusL. N.Z.J. Public Health $25,494-497,2001$

3b. Kessler R.C., Anarew's G., Colpe L...., Hiripi E., Mroczek D.K., Normand S.L.I., Walter's E.E. 
A. Jarby, P. Hay. F. Quirk, el al.

Zaslavsky A.M.: Sloorl screening scales to monitor population prevalences and trends in non-specific psychological distress. Psychol. Med., 32, 959-976, 2002.

37. Mond J.M., Hay P.J., Rodgers B., Owen C.. Beumont P.J.V.: Assessing quality of life in eating cisorder patients. Qutal. Life Res., 14, 171-178, 2005.

38. Hay P.J., Bacaltchuk J., Stelano S.: Psychntherapy for bulimia nervosa and binging. The Cochrane Database of Systematic Reviews, Issue 3, Art No.:CD000562. DOl:10.1002/14651858.CD000562.pub2. , 2004.
39. Ball K., Brown W., Crawford D.: Who does not gain weight? Prevalience and predictors of weight maintenance in young women. Int. J. Obes., 26, 1570-1578, 2002.

40. Carter F.A., Bulik C.M., Joyce P.R.: Direction of weight change in depression. J. Affect. Disurd., 30, 57-60, 1994.

41. Stice E., Fisher M., Lowe M.R.: Are dietary restraint scales valid measures of acute dietary restriction? Unobsrusive observational data suggest not. Psychol. Assess., 16, 51-59, 2004. 